هبلة كايسة الآداب الآداب وعلوم اللغة

ومدة النشـر العلمي كلية الآداب - جامعة القاهرة

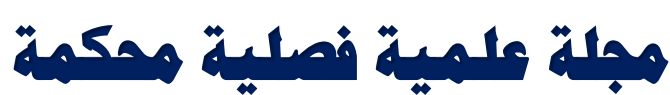

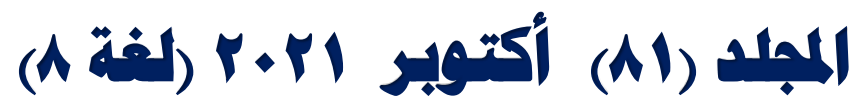





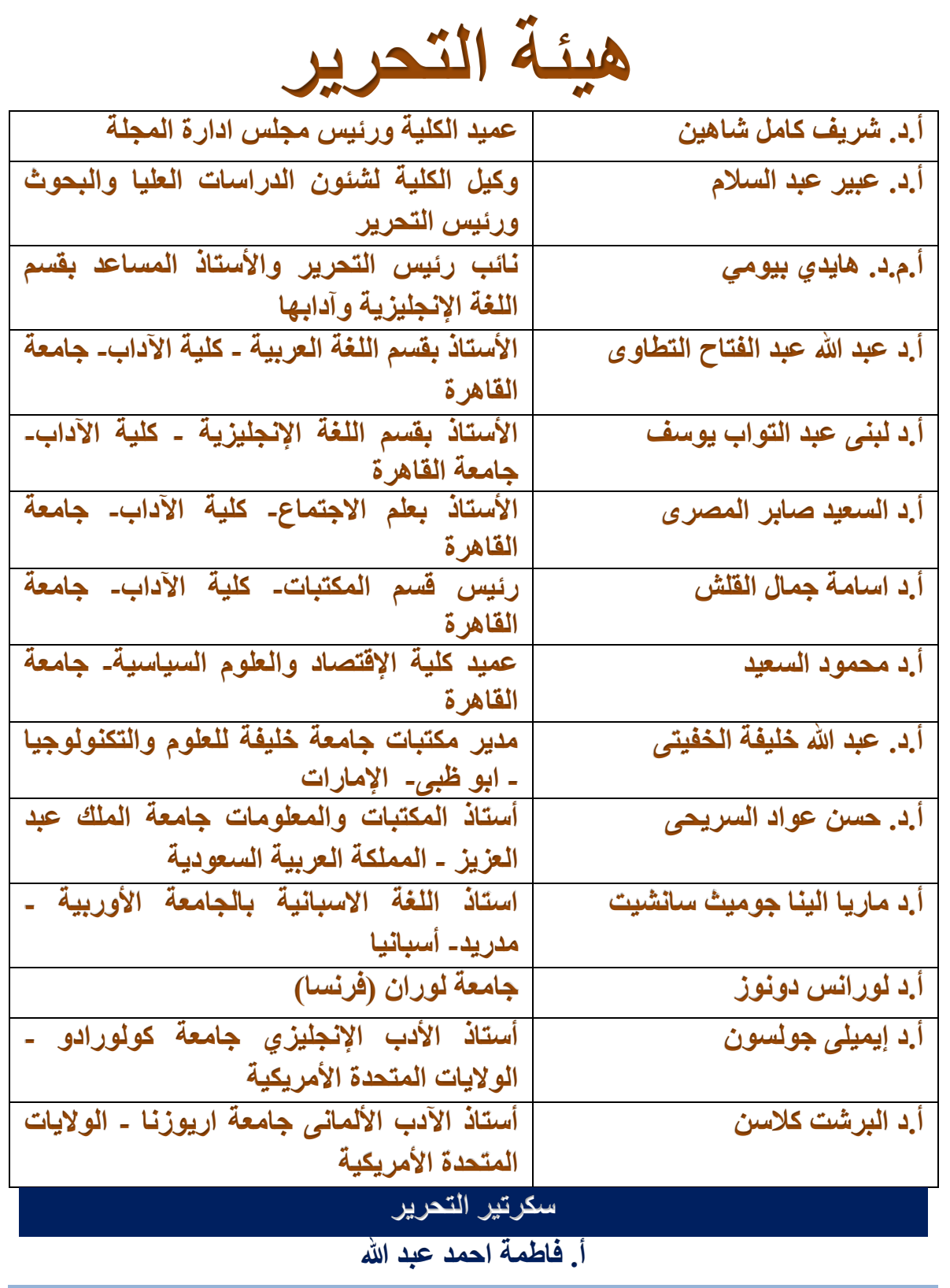

المراسلات: توجه جميع المراسلات إلى الأستاذ الاكتور رئيس تحرير مجلة كلية الآداب-

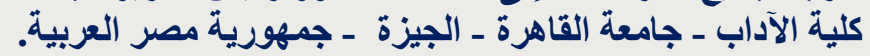

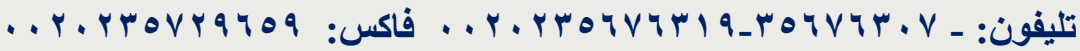
E-mail: jfa@cu.edu.eg 



\section{الميئة الاستشارية}

$$
\begin{aligned}
& \text { ا.د.عبد الله الغتيم } \\
& \text { رئيس الجمعية الجغرافيةـ الكويت } \\
& \text { ا.د. ابراهيم شبوح الجيوح }
\end{aligned}
$$

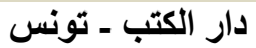

$$
\begin{aligned}
& \text { •د. إيبا نخيلوس موتسوبولوس } \\
& \text { جامعة أثينا- اليونان } \\
& \text { ا.د. سعد محمد سعد } \\
& \text { جامعة بابلو دي أولابيدي - إسباتيا }
\end{aligned}
$$

\section{المراجعة الافمية (العربية)}

محمود السبد طه

\section{المراجعة الاغوية (الأجنبية)}

د. دايدي محمد بيومي

كلية الآداب - جايدي محمة القاهية

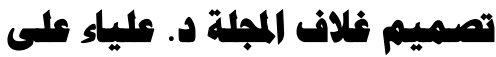

كلية التربية التوعية، جامعة القاهرة 
• جميـع حقـوق الطبـع و النشـر والتوزيـع محفوظــة لمجلـة كليـة

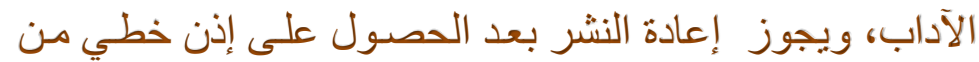

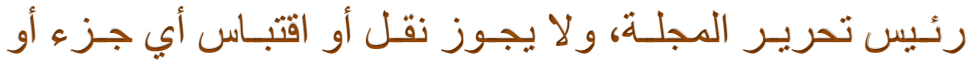
استنساخه تقليديًّا أو إلكترونيَّا إلا بمو افقة كتابية من رئيس تحرئ تحرئ المجلة. هيثم ترتيب المو اد العلمية في كل عدد وفقًا لاعثبار ات فنية.

$$
\text { رقم الإيداع بدار الكتب المصرية }
$$

ISSN: 1012-60150 


\section{هبلة كليسة الآداب}

\section{قواعد النشر فى هجلة كلية الآداب - جاهعة القاهرة}

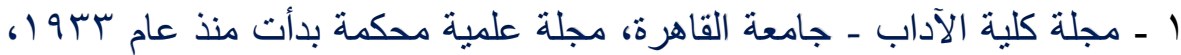

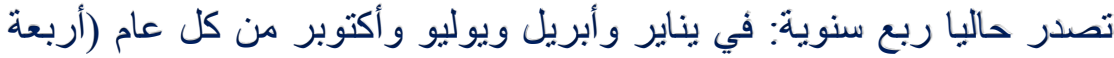

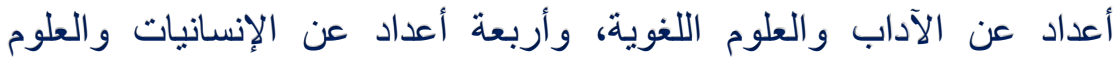
(الاجتماعية).

r - يُقبل للنشر بهذه المجلة البحوث و الدراسات و المقالات التي تتميز بالأصالة

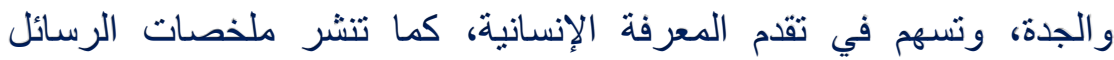

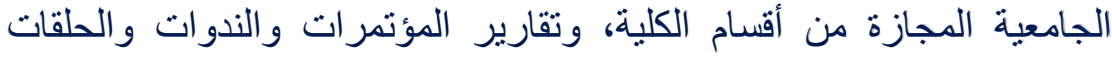

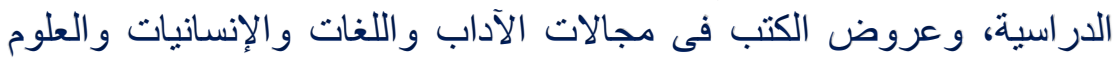
الاجتماعية.

r - يلتزم الباحث عند تقديم البحث بالمواصفات المعمول بها بالمجلة، والمنشورة على موقع الكلية (http://arts.cu.edu.eg).

عـ تخضع الأعمال المقدَّمة للتحكيم العلمي السري وفقعًا للنظام المتبع في المجلة.

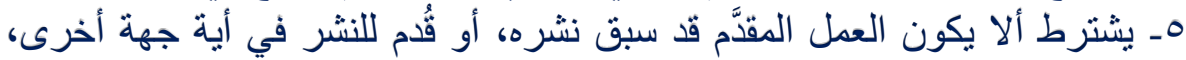

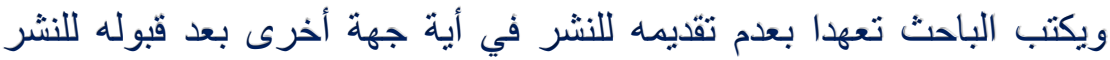
بالمجلة. 7- لا يجوز إعادة نشر محتويات هذه المجلة، إلا بعد الحصول على إذن كتابي من هيئة التحرير. V- V- لا تُرد أصول الأعمال المقدمة للمجلة، سواء قُبلت للنشر أو لم تُقبل.

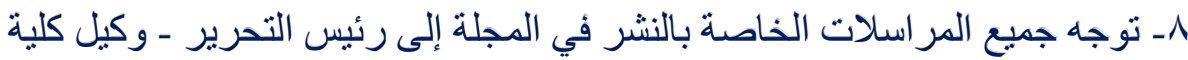

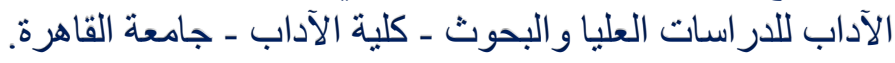
9ـ الآر اء الواردة في المجلة تعبر عن وجهات نظر أصحابها. 
